\title{
Effective Doping of Rare-earth Ions in Silica Gel: A Novel Approach to Design Active Electronic Devices
}

\author{
D. Haranath*, Savvi Mishra, Amish G. Joshi, Sonal Sahai, Virendra Shanker
}

(Received 21 June 2011; accepted 4 August 2011; published online 31 August 2011.)

\begin{abstract}
Eu}^{3+}$ luminescence spectroscopy has been used to investigate the effective doping of alkoxide-based silica $\left(\mathrm{SiO}_{2}\right)$ gels using a novel pressure-assisted sol-gel method. Our results pertaining to intense photoluminescence (PL) from gel nanospheres can be directly attributed to the high specific surface area and remarkable decrease in unsaturated dangling bonds of the gel nanospheres under pressure. An increased dehydroxylation in an autoclave resulted in enhanced red $(\sim 611 \mathrm{~nm}) \mathrm{PL}$ emission from europium and is almost ten times brighter than the $\mathrm{SiO}_{2}$ gel made at atmospheric pressure and $\sim 50^{\circ} \mathrm{C}$ using conventional Stöber-Fink-Bohn process. The presented results are entirely different from those reported earlier for $\mathrm{SiO}_{2}: \mathrm{Eu}^{3+}$ gel nanospheres and the origin of the enhanced PL have been discussed thoroughly.
\end{abstract}

Keywords: Luminescence; Nanophosphor; Short-range order; Electron microscopy

Citation: D. Haranath, Savvi Mishra, Amish G. Joshi, Sonal Sahai and Virendra Shanker, "Effective Doping of Rare-earth Ions in Silica Gel: A Novel Approach to Design Active Electronic Devices", Nano-Micro Lett. 3 (3), 141-145 (2011). http://dx.doi.org/10.3786/nml.v3i3.p141-145

\section{Introduction}

Luminescent materials have been utilized widely in applications involving lighting to sensing [1]. The photoluminescence $(\mathrm{PL})$ properties of silica have also been an important topic of research for a long time, but the difficulty in the incorporation of rare-earth $(\mathrm{RE})$ ions attached covalently to the silica $\left(\mathrm{SiO}_{2}\right)$ network is still considered a great challenge. The weak PL bands with peak energies $\sim 1.9-4.3 \mathrm{eV}$ for both bulk and thin films of $\mathrm{SiO}_{2}$ have been reported [2]. The sol-gel method has been used to prepare nanomaterials in the form of powders, films, fibers and monoliths that are based on various metal alkoxides [3]. It has been observed that monodisperse silica nanospheres formed by hydrolysis and condensation of alkoxides using Stöber-Fink-Bohn (SFB) process gives negligible luminescence. Incorporation of inorganic luminescent centres into SFB spheres has been demonstrated by some research groups [4] us- ing RE ions, quantum dots and organic flurophores, but the procedure requires multiple processing steps and use of expensive and toxic ligands. During the last few years, there have been few reports [5-10] on intense PL emission in the visible region of the electromagnetic spectrum, by several different nanostructured materials that are highly disordered such as nanowires, porous silicon, silica-based mesoporous fractals, ferroelectrics with $\mathrm{ABO}_{3}$ type and $\mathrm{AWO}_{4}$-type perovskite structures $(\mathrm{A}=\mathrm{Ca}, \mathrm{Ba}, \mathrm{Sr})$; and many more. The origin of this type of luminescence is always attributed to unsaturated chemical bonds in these nanostructures. In case of ferroelectrics, as their energy band gaps are located $\sim 3-4 \mathrm{eV}$, the PL emission in the visible region was correlated to their highly disordered states and many localized electronic levels present within the optical gap, causing luminescence [6]. Since $\mathrm{SiO}_{2}$ gel is a well-studied system [11] having visible transparency and significant absorption peak lying in the ultra-violet

National Physical Laboratory, Council of Scientific and Industrial Research, Dr K S Krishnan Road, New Delhi, 110 012, India

*Corresponding author. E-mail: haranath@nplindia.org 
region, the introduction of dopant ions act as a perturbation to the well-studied system leading to interesting optical properties. The RE ions are used as probes in the sol-gel method due to their sensibility to change with the surrounding matrix probing the local structure $[12,13]$. Thus derived $\mathrm{SiO}_{2}$ and organically modified matrix composites could be the main precursor to prepare many RE based smart optical materials [14].

In this paper, we propose a novel methodology to prepare alkoxide-based silica gel nanospheres doped with $\mathrm{Eu}^{3+}$ ions that show enhanced PL brightness, uniform size distribution and improved quantum efficiencies. This is a process by which highly disordered but doped silica gels could be effectively made useful for practical applications involving luminescence. It has already been evidenced that high pressure and temperature leads to more closely packed structures [14]. The presented analogy is unique and could be extended to many crystalline and non-crystalline phosphor based systems to design new family of sol-gel based nanocomposites, having a wide variety of applications in lasers, chemical sensing, waveguides, bioanalytical assays, blood flow monitoring and effectively harvesting the solar energy for improving the solar cell efficiency.

\section{Experimental}

Silica nanospheres were prepared with its surface modified by sol-gel method and studied through the incorporation of Europium (III) ions in two different ways. The europium nitrate $\left(\mathrm{EuNO}_{3}\right)$ was mixed with sufficient ethanol (EtOH) and this was added to tetraethylorthosilicate (TEOS). The stoichiometric amount of water, which is essential to carryout hydrolysis reaction, was added drop wise under continuous stirring. Prior to gelling the low and high resolution transmission electron microscopy (TEM) images of colloidal silica solution (also called silica sol) were taken at a magnification of 125 and $400 \mathrm{kX}$, respectively as shown in Fig. 1. The silica particles observed are almost spherical with an average cluster size of $\sim 5 \mathrm{~nm}$. The schematic of the $\mathrm{SiO}_{2}$ gel network [11] and the probable description of pore and particle sizes were illustrated in Fig. 1(c). The silica sol was then divided in two halves for a systematic experimentation. For the first experiment, one of the solution containing vials was allowed to gel at atmospheric pressure (1 bar) and a controlled oven temperature of $\sim 50^{\circ} \mathrm{C}\left( \pm 0.1^{\circ} \mathrm{C}\right)$. In the second case the solution was kept in an autoclave, subjected to high temperature and pressure at $\sim 150^{\circ} \mathrm{C}$ and 120 bars, respectively for about 5 hours. It was intentional to keep the processing time same for both the cases. Once the wet silica gels were obtained, $\mathrm{SiO}_{2}: \mathrm{Eu}^{3+}$ nanospheric powders were obtained by drying the gels overnight in vacuum oven at $\sim 55^{\circ} \mathrm{C}$. All the samples were studied using morphology, composition evaluation, UV-VIS absorption and luminescence spectroscopy techniques.
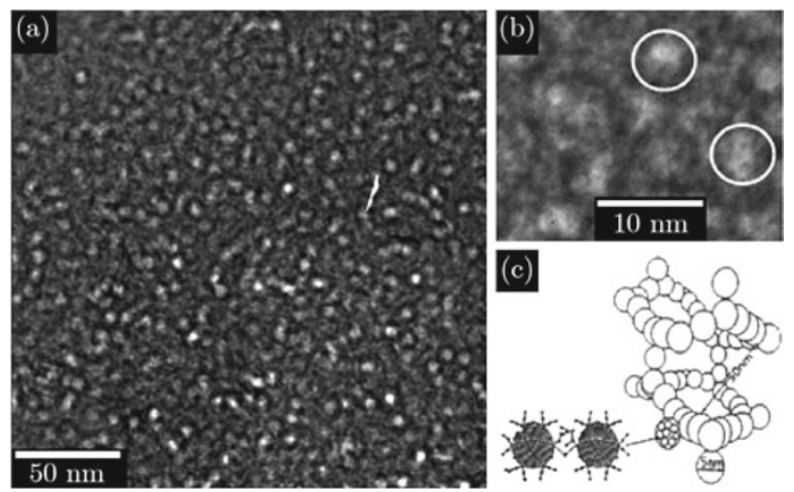

Fig. 1 (a) TEM and (b) HRTEM images of silica sol particles aged for 5 hours at room temperature, $25^{\circ} \mathrm{C}$; (c) schematic illustration of gel network structure showing the pore and particle sizes (Courtesy from ref. [11]).

For TEM observations, the samples were redispersed in methanol by ultrasonic treatment and dropped on carbon-copper grids. TEM images were collected using a Tecnai G ${ }^{2}$ F30 S-Twin (FEI; Super Twin lens with $\mathrm{C}_{\mathrm{S}}=1.2 \mathrm{~mm}$ ) instrument operating at an accelerating voltage at $300 \mathrm{kV}$, having a point resolution of $0.2 \mathrm{~nm}$ and lattice resolution of $0.14 \mathrm{~nm}$ ) with an EDAX attachment. Program Digital Micrograph (Gatan) was used for image processing. Scanning electron microscopy was performed using Zeiss EVO MA10.

X-ray diffraction (XRD) of the powder sample was performed using Bruker D-8 advance powder X-ray diffractometer with $\mathrm{CuK}_{\alpha}$ radiation operated at $35 \mathrm{kV}$ and $30 \mathrm{~mA}$. All the samples showed the amorphous nature.

X-ray Photoelectron Spectroscopy (XPS) studies have been carried out using a Perkin Elmer 1257 model, at $300 \mathrm{~K}$ with a non-monochromatic AlKa line at $1486.6 \mathrm{eV}$. During photoemission studies, small specimen charging was observed which was later calibrated by assigning the $\mathrm{C} 1 \mathrm{~s}$ signal at $285 \mathrm{eV}$.

The room temperature photoluminescence (PL) spectra were recorded using an Edinburgh Luminescence Spectrometer (Model F900) equipped with a xenon lamp. The excitation and emission spectra were recorded in the fluorescence mode over the range of 300$700 \mathrm{~nm}$.

\section{Results and discussion}

It is important to highlight the pressure-assisted hydrothermal/solvothermal process for the preparation of variety of nanoparticles of oxides and chalcogenide materials. The solution based nanomaterial synthesis often involves reactions carried out near the boiling point 
of the solvent. This may lead to poor quality of the nanomaterial and less yield. In order to obtain crystalline, monodisperse nanoparticles, it is always necessary to work at relatively high temperatures and pressures. Use of acid digestion bomb (commonly called Autoclave) is the best alternative to work with. Details of the autoclave synthesis of intrinsic silica gels have been reported extensively by Haranath et al. since 1996. In the current case, rare-earth (RE) doped silica gels were made under pressure at elevated temperatures as described in latter sections. This method of preparation, which is based on pressure-assisted sol-gel method, has compatibility in modifying the coordinating environment of RE (dopant) ions so that the loss in energy of the excited states via. non-radiative mechanism is minimum. The x-ray diffraction pattern of $\mathrm{Eu}^{3+}$ doped $\mathrm{SiO}_{2}$ gel powder depicted in Fig. 2 clearly shows a broad hump at $\sim 23^{\circ}$ indicating the complete amorphous nature of the $\mathrm{SiO}_{2}$ nanospheres. SEM images shown in inset of Fig. 2 illustrate the quality of the nanospheres with respect to their size and shapes. In other words, the conventional sol-gel method leads to a broad distribution of particle sizes in the range 10-50 nm (Fig. 2(a)) whereas the pressure assisted solgel method has resulted in almost uniform particles ( $15 \mathrm{~nm})$ with spherical shape (Fig. 2(b)). This establishes the fact that high pressure and temperature leads to more closely packed structures and increased charge transfer energies that are efficiently transferred to the $\mathrm{Eu}^{3+}$ ions. The TEM and scanning electron micrographs (SEM) reveal that the optimization of experimental and processing parameters allow microscopic preparation of uniform silica nanospheres.

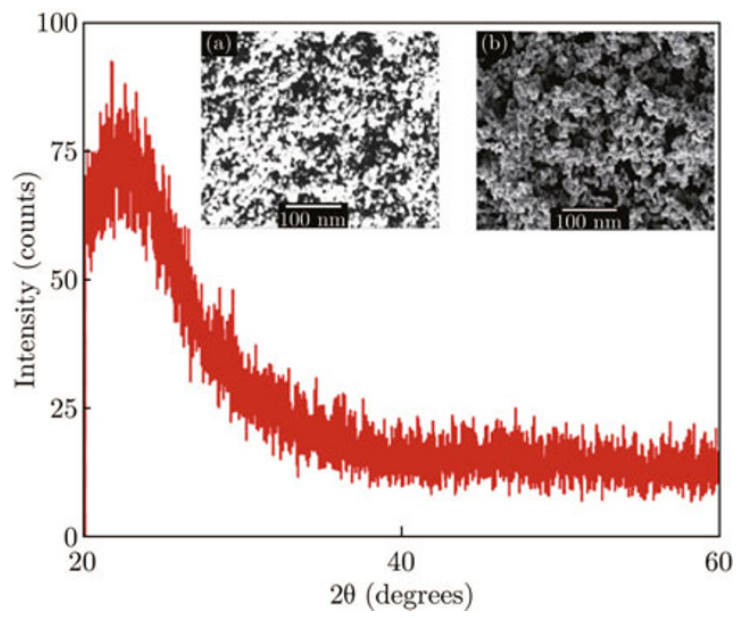

Fig. 2 X-ray diffraction (XRD) pattern of $\mathrm{SiO}_{2}$ gel powder at room temperature $\left(\sim 25^{\circ} \mathrm{C}\right)$ indicating the amorphous nature of the gel under study. The insets shows the SEM micrographs of $\mathrm{SiO}_{2}: \mathrm{Eu}$ gels prepared at (a) atmosphere pressure ( 1 bar) and $50^{\circ} \mathrm{C}$; and (b) 120 bars and $150^{\circ} \mathrm{C}$, respectively.
Moreover, the chemical composition and the relevant surface chemistry of $\mathrm{SiO}_{2}: \mathrm{Eu}^{3+}$ nanospheres were analyzed using x-ray photoelectron spectroscopy (XPS). The XPS observations revealed three peaks corresponding to the elements $\mathrm{Si}, \mathrm{O}$ and $\mathrm{Eu}$, respectively. Pass energy for general survey scan and core level spectra was kept at 143.05 and $71.55 \mathrm{eV}$ respectively. Surface contamination was removed by Ar ions with $4 \mathrm{keV}$ beam energy. Sputtering performed in raster mode with emission current of $20 \mathrm{~mA}$ for $5 \mathrm{~min}$ at base pressure $4.5 \times 10^{-7}$ torr. Figure 3 shows the survey spectra of $\mathrm{SiO}_{2}: \mathrm{Eu}^{3+}$ nanospheres acquired in the range of 0 $1200 \mathrm{eV}$. During photoemission studies, small specimen charging was observed, which was later calibrated by assigning the $\mathrm{C} 1 \mathrm{~s}$ signal at $285 \mathrm{eV}$. Survey spectra after sputtering show sharp peaks of C 1s $(285 \mathrm{eV}), \mathrm{O} 1 \mathrm{~s}$ $(537 \mathrm{eV})$. Two clear distinct state of Eu were observed at 1171 and $1141 \mathrm{eV}$ for $\mathrm{Eu} 3 \mathrm{~d}_{3 / 2}$ and $3 \mathrm{~d}_{5 / 2}$ respectively. The separation between two states is because of spin-orbit splitting. Inset of Fig. 3 shows the $\mathrm{Si}(2 \mathrm{p})$ core level spectra. The value of elemental $\mathrm{Si}(2 \mathrm{p})$ is $99.15 \mathrm{eV}$, since, appearance of $\mathrm{Si}(2 \mathrm{p})$ at $104 \mathrm{eV}$ confirms the $\mathrm{Si}$ exist in $\mathrm{SiO}_{2}$ state. The binding energies of various elements match very well with the peaks observed for standard $\mathrm{SiO}_{2}: \mathrm{Eu}^{3+}$. The presence of $\mathrm{C}$ is due to the air atmosphere and the organics used for the preparation of $\mathrm{Eu}^{3+}$ doped in silica matrix.

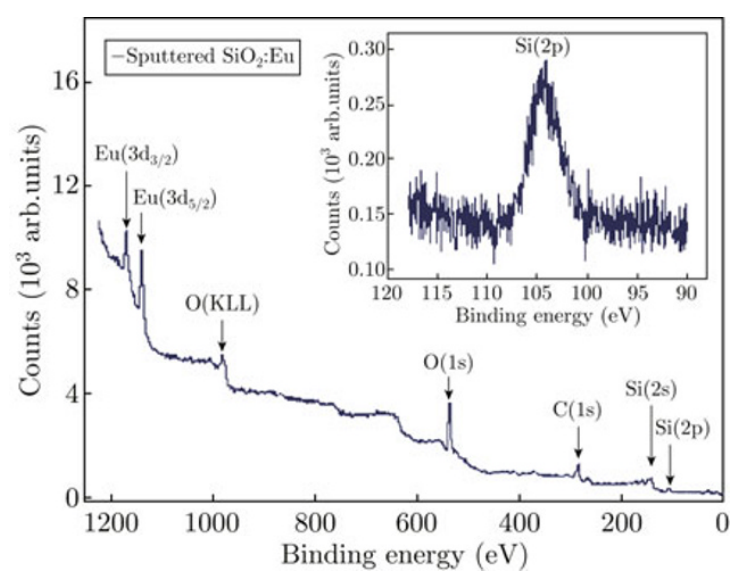

Fig. 3 XPS survey scan spectra of sputtered and nanoparticles of $\mathrm{SiO}_{2}: \mathrm{Eu}^{3+}$ recorded with photon energy of $\mathrm{AlK} \alpha$ $(\mathrm{h} v=1486.6 \mathrm{eV})$, Inset shows the $\mathrm{Si}(2 \mathrm{p})$ core level.

Figure 4 shows the UV-VIS absorbance spectra of $\mathrm{Eu}^{3+}$ doped $\mathrm{SiO}_{2}$ gel samples prepared at $50^{\circ} \mathrm{C}, 1$ bar; and $150^{\circ} \mathrm{C}, 120$ bars, respectively. The spectra are the strong indicative two findings. One is being the reduction of surface states of the gel nanospheres and other being the maintenance of almost the same size for the gel particles even after subjecting to high pressure and temperature cycles. The same has been evidenced by the absorption peaks indicated in the inset of Fig. 4. 


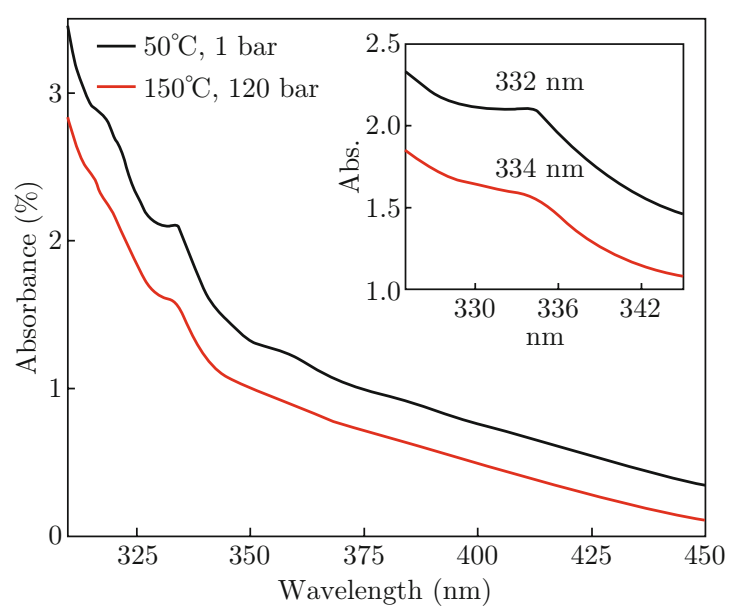

Fig. 4 Absorbance spectra of Eu doped- $\mathrm{SiO}_{2}$ samples prepared at atmosphere pressure (1 bar) and 120 bars and $150^{\circ} \mathrm{C}$, respectively. Inset shows the expanded version of the absorption peaks.

The observation of weak photoluminescence (PL) at room temperature in various amorphous silica nanostructures has been reported in the literature [15-18] but not sufficient to use for any fundamental or potential application. Figure 5 shows the PL excitation (PLE) and PL spectra from $\mathrm{Eu}^{3+}$ doped and baked $\mathrm{SiO}_{2}$ gel in an autoclave respectively. It is known that the surface states and unsaturated dangling bonds play a critical role in determining the overall PL characteristics of nanostructures. If the silica gel is prepared with a rare-earth dopant $\left(\mathrm{Eu}^{3+}\right.$ in the present case), the $\mathrm{PL}$ is dominated by the radiative transitions $\left({ }^{5} \mathrm{D}_{0} \rightarrow{ }^{7} \mathrm{~F}_{\mathrm{j}}\right.$, $\mathrm{j}=0-3)$ from the levels of $\mathrm{Eu}^{3+}$ ions [19] as shown in the inset of Fig. 5. The emission spectra of $\mathrm{Eu}^{3+}$ doped $\mathrm{SiO}_{2}$ gels prepared at $50^{\circ} \mathrm{C}, 1$ bar; and $150^{\circ} \mathrm{C}, 120$ bars, were shown in Fig. 5. For recording the PL spectra the excitation energy has been fixed as $395 \mathrm{~nm}$ which is the ${ }^{5} \mathrm{~L}_{6}$ level of $\mathrm{Eu}^{3+}$ ligand band. The PL from the $\mathrm{Eu}^{3+}$ doped $\mathrm{SiO}_{2}$ gel prepared at atmospheric pressure (1 bar) and $50^{\circ} \mathrm{C}$ was found to be weak and inefficient for any practical application, whereas the PL intensity from the gel turn out to be much stronger ( $>10$ times) when the sol was gelled under high temperature $\left(150^{\circ} \mathrm{C}\right)$ and pressures (120 bars) inside an autoclave. Moreover, the PLE spectrum also became narrower under autoclave treated gel sample, which indicate that there is a remarkable decrease in unsatisfied chemical bonds in the final product. The most intense line at $\sim 611 \mathrm{~nm}$ corresponds to the hypersensitive transition between the ${ }^{5} \mathrm{D}_{0}$ and ${ }^{7} \mathrm{~F}_{2}$ level of the $\mathrm{Eu}^{3+}$ ions and will be relatively strong if the surrounding symmetry is low. In the sense, it is generally admitted that the ratio of the emission intensities $\mathrm{R}=\mathrm{I}\left({ }^{5} \mathrm{D}_{0} \rightarrow{ }^{7} \mathrm{~F}_{2}\right) / \mathrm{I}\left({ }^{5} \mathrm{D}_{0} \rightarrow{ }^{7} \mathrm{~F}_{1}\right)$ is an asymmetry parameter for the $\mathrm{Eu}^{3+}$ sites and a measure of the extent of its interaction with the surrounding ligands [20]. This indicates that the environment of the $\mathrm{Eu}^{3+}$ is dictated by the nano- $\mathrm{SiO}_{2}$ host under high pressure and temperature conditions. In addition, broad excitation peaks observed between 250-500 nm became distinct and sharp for the sample made under high pressures. The sharp peaks in the PL and PLE spectra of $\mathrm{SiO}_{2}$ :Eu nanospheres may be due to quantum confinement effects related to size restrictions. A combination of unique features of high surface-to-volume ratios, monodispersion and strong photoluminescence suggest that these silica nanospheres will find many interesting applications in semiconductor photophysics, inorganic light emitting diodes, solar cells, environmental remediations and optoelectronic devices.

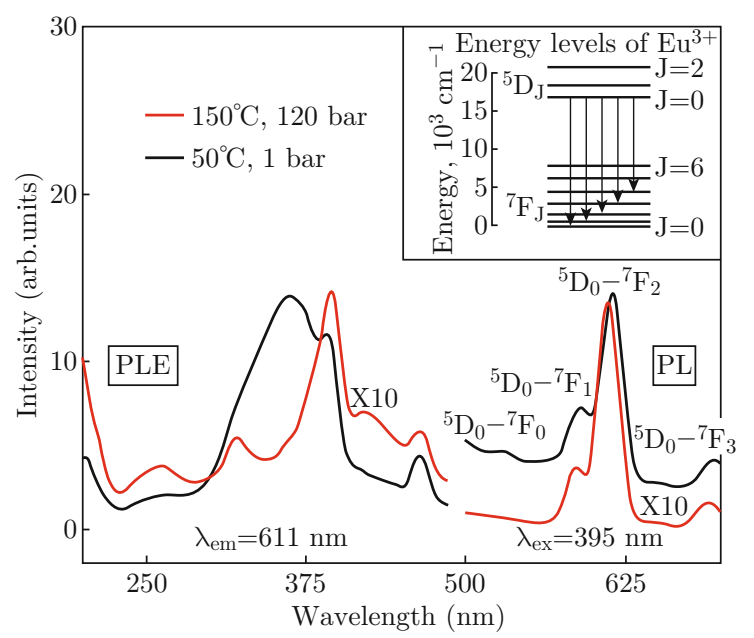

Fig. 5 PLE and PL spectra of $\mathrm{SiO}_{2}$ :Eu gels made at (a) $50^{\circ} \mathrm{C}, 1$ bar and (b) 120 bars and $150^{\circ} \mathrm{C}$, respectively. Inset shows the mechanism of $\mathrm{Eu}^{3+}$ transitions.

\section{Conclusions}

In conclusion, we have demonstrated a mechanism by which photoluminescence enhancement in $\mathrm{SiO}_{2}: \mathrm{Eu}^{3+}$ phosphor nanospheres could be successfully achieved using pressure-assisted sol-gel method. The observed red emission is from typical ${ }^{5} \mathrm{D}_{0}-{ }^{7} \mathrm{~F}_{2}$ transition of $\mathrm{Eu}^{3+}$ and is found to be almost ten times brighter than the gel made at atmospheric pressure (1 bar) and $\sim 50^{\circ} \mathrm{C}$ using Stöber-Fink-Bohn process. This kind of process is highly desirable for many crystalline and noncrystalline materials system wherein the doping is inappropriate. This may lead to design many fundamental and novel optoelectronic applications.

\section{Acknowledgments}

The authors (DH, SM and SS) gratefully acknowledge the Department of Science and Technology (DST), Ministry of Science and Technology, Government of India for their respective fellowships under various sponsored projects to carryout the work. 


\section{References}

[1] J. Wang, Y. Yoo, C. Gao, I. Takeuchi, X. Sun, H. Chang, X. D. Xiang and P. G. Schultz, Science 279, 1712 (1998).

[2] L. S. Liao, X. M. Bao, X. Q.Zheng, N. S. Li and N. B. Min, Appl. Phys. Lett. 68, 850 (1996). http://dx. doi.org/10.1063/1.116554

[3] M. A. Silva, D. C. Oliveira, A. T. Papacidero, C. Mello, E. J. Nassar, K. J. Ciuffi, and H. C. Sacco, J. Sol-Gel Sci. Tech. 26, 329 (2003).

[4] E. J. Nassar, C. R. Neri, P. S. Calefi and O. A. Serra. J. Non-Cryst. Solids 247, 124 (1999). http://dx. doi. org/10.1016/S0022-3093(99)00046-0

[5] A. S. Zyubin, Y. D. Glinka, A. M. Mebel, S. H. Lin, L. P. Hwang and Y. T. Chen, J. Chem. Phys. 116, 281 (2002). http://dx.doi.org/10.1063/1.1425382

[6] Y. D. Glinka, A. S. Zyubin, A. M. Mebel, S. H. Lin, L. P. Hwang and Y. T. Chen, Euro. Phys. J. D 16, 279 (2001). http://dx.doi.org/10.1007/s100530170110

[7] D. Haranath, N. Gandhi, S. Sahai, M. Husain and V. Shanker, Chem. Phys. Lett. 496, 100 (2010). http:// dx.doi.org/10.1016/j.cplett.2010.07.015

[8] A. R. Guichar, D. N. Barsic, S. Sharma, T. I. Kamins and M. L. Bronersma Nano Lett. 6, 2140 (2006).

[9] V. S. Kortov, A. F. Zatsepin, S. V. Gurbonov and A. M. Murzakaev, Phys. Solid State 48, 1273 (2006). http://dx.doi.org/10.1134/S1063783406070092

[10] D. Haranath, V. Shanker, H. Chander and P. Sharma, J. Phys. D: Appl. Phys. 36, 2244 (2003). http://dx. doi.org/10.1088/0022-3727/36/18/012

[11] C. J. Brinker and G. W. Scherer, Sol-Gel Science Academic Press, Boston (1990).
[12] J. C. G. Bunzil and G. R. Choppin, Lanthanide Probe in Life, Chemical and Earth Sciences, Elsevier, New York (1989).

[13] D. Levy, R. Reisfeld and D. Avnir, Chem. Phys. Lett. 109, 593 (1984). http://dx.doi.org/10.1016/ 0009-2614 (84) 85431-7

[14] D. Haranath, S. Sahai, S. Singh, A. G. Joshi, M. Husain and V. Shanker, J. Mater. Chem. 21, 9471 (2011). http://dx.doi.org/10.1039/c1jm11874a

[15] S. Frank, P. Poncharai, Z. L. Wang and W. A. de Heer, Science 280, 1744 (1998). http://dx.doi.org/ 10.1126/science. 280.5370.1744

[16] A. P. Alivisatos, Science 71, 933 (1996).

[17] P. Kim and C. M Lieber, Science 286, 2148 (1999). http://dx.doi.org/10.1126/science. 286.5447. 2148

[18] W. Han, S. Fan, Q. Li and Y. Hu, Science 277, 1287 (1997). http://dx.doi.org/10.1126/science. 277.5330 .1287

[19] L. Xu, B. Wei, Z. Zhang, Z. Lu, H. Gao and Y. Zhang, Nanotechnology 17, 4327 (2006).

[20] Z. Andric, M. D. Dramicanin, V. Jokanovic, T. Dramicanin, M. Mitric and B. Viana, J. Optoelecton. Adv. Mater. 8, 829 (2006).

[21] X. L. Wu, G. G. Siu, S. Tong and D. Feng, Appl. Phys. Lett. 69, 523 (1996). http://dx.doi.org/10.1063/1. 117774

[22] V. Lehmann and U. Gosele, Appl. Phys. Lett. 58, 856 (1991). http://dx.doi.org/10.1063/1.104512

[23] W. J. Zhang, X. L. Wu, J. Y. Fan, G. S. Huang, T. Qiu and P. K. Chu, J. Phys. Condens. Matter 18, 9937 (2006). http://dx.doi.org/10.1088/0953-8984/18/ 43/015 